\title{
Zone refining of cadmium and related characterization
}

\author{
N R MUNIRATHNAM*, D S PRASAD, CH SUDHEER, J V RAO and \\ T L PRAKASH
}

Centre for Materials for Electronics Technology (C-MET), IDA, Phase-II, Cherlapally, HCL Post, Hyderabad 500051 , India

MS received 4 November 2003; revised 14 February 2005

\begin{abstract}
We present the zone refining results of cadmium using horizontal resistive zone refiner under constant flow of moisture free hydrogen gas. The boron impurity in cadmium can be avoided using quartz (GE 214 grade) boat in lieu of high pure graphite boat. The analytical results using inductively coupled plasma optical emission spectrometry (ICPOES) show that majority of the impurities are less than the detection limits. Comparatively, zinc is the most difficult impurity element to remove in cadmium matrix by zone refining.
\end{abstract}

Keywords. High pure cadmium; zone refining; segregation of impurities.

\section{Introduction}

The carrier concentration in the range of $10^{14}$ to $10^{15} / \mathrm{cm}^{3}$, is adequate for the manufacture of most of the devices. Further lowering of the carrier concentration is desirable, which however, requires production of materials with higher purity. For example, for an efficient infrared (IR) detector, the carrier concentration in mercury cadmium telluride (MCT) must be low, the mobility should be high and excited-state life time must be long, which can be possible by avoiding deep energy levels in the energy gap, created by impurities, in that particular compound semiconductor (Zanio 1978). The background levels of electrically active impurities for IR applications should be in the range of 0.3-15 ppb in MCT (Capper and Harris 1997), where cadmium is only one of the metals in addition to tellurium and mercury. Therefore, presence of impurities in MCT has a negative effect in device characteristics. Cadmium is one of the most difficult metals to zone refine, because of its low melting point $\left(\sim 320^{\circ} \mathrm{C}\right)$, high thermal conductivity $\left(\sim 0.9 \mathrm{~W} \mathrm{~cm}^{-1} \mathrm{~K}^{-1}\right.$ at room temperature) and high thermal expansion ( 7.5\% from solid to liquid) (Bult et al 1987; Kovalevsky and Shelpakova 2000). Also, it is difficult to eliminate all the impurities using a single purification process due to efficient elimination of prominent impurities resulting from differentials in vapour pressure in vacuum distillation, the closeness of the segregation coefficients to unity in crystallization, etc. However, in case of cadmium purification, crystallization is applied as a final refining process, especially multiple zone refining and gradient crystallization with material removal from the ends of the zone refined ingot, where the impurities accumulate (Kuchar et al 1996), to achieve $6 \mathrm{~N}$ and above

*Author for correspondence (munirathnamnr@yahoo.co.in) pure material. Indigenous cadmium purified by horizontal resistive zone refiner using ultrapure graphite (99.999\%) boat under static hydrogen ambient and the impurities analysed using spark source mass spectrometry (SSMS) results have been reported (Mathur and Singh 1989). It is well known that by using graphite boat during zone refining, the boron and carbon impurities are unavoidable in the purified material. Therefore, with a view to reduce the impurities further in indigenous cadmium obtained from local market, it is vacuum distilled and purified in a quartz boat (GE 214 grade) using automated horizontal resistive zone refiner under dynamic hydrogen gas flow. The hydrogen flow is expected to minimize oxygen contamination in purified cadmium, which may otherwise result in breakage of expensive quartz tube while growing compound semiconductors.

\section{Experimental}

The process flow sheet for cadmium purification is given in figure 1 . The cadmium of $2 \mathrm{~N}$ purity available from the local market was purchased and cleaned using dilute acids and nanopure water and subsequently vacuum distilled at our laboratory to achieve nearly $5 \mathrm{~N}$ purity of cadmium. The technical details of cadmium vacuum distillation process is not in the scope of this paper and therefore not discussed here. The chunks of vacuum distilled cadmium was used as input material for zone refining by uniformly melting around $450^{\circ} \mathrm{C}$ under hydrogen flow in a quartz boat of length $560 \mathrm{~mm}$, breadth $33 \mathrm{~mm}$ and $20 \mathrm{~mm}$ height with $1.5 \mathrm{~mm}$ thickness. The cooled cadmium ingot was taken out and momentarily etched using dil. $\mathrm{HNO}_{3}$ and nanopure water under class 100 laminar air flow wash bench. The ingot was subsequently dried using nitrogen gas before loading into the quartz tube for zone refining. 
Similar experiment using graphite boat (GLM 85 grade) was tried in this laboratory. Stable zones are difficult to form in cadmium bar, because of high thermal conductivity of both cadmium and graphite, as also, the boron content was found to be slightly increased to $\sim 1 \mathrm{ppm}$ from $<0.1 \mathrm{ppm}$ after first cycle. However, when graphite boats from ultrapure graphite, USA were used, boron content remained at $<0.006$ ppma in cadmium metal after zone refining (Mathur and Singh 1989). Recently, quartz boats for purification of cadmium by zone refining has become more promising especially while producing ultrapure cadmium for electronic applications (Capper and Harris 1997). Zone refining equipment used for purification of cadmium was similar to that of tellurium (Munirathnam et al 2002), barring zone temperature which was maintained around $15 \%$ more than melting point, $T_{\mathrm{m}}$ of cadmium with an accuracy of $\pm 1^{\circ} \mathrm{C}$ using temperature controllers. The hydrogen gas (grade I) was purified using moisture absorber before letting into the zone refining quartz tube containing cadmium ingot through stainless steel (SS) tube and flanges. The experiment was carried out with a constant zone speed of $30 \mathrm{~mm} / \mathrm{h}$. The temperature profile of the heater used for zone refining is shown in figure 2 and the zone width was found to be around $65 \mathrm{~mm}$. Other experimental parameters included 15 molten zone passes in each cycle and at the end of each cycle, one zone length portion on either side of the ingot was cut and about $70 \%$ of the middle fraction (MF) was removed using a special

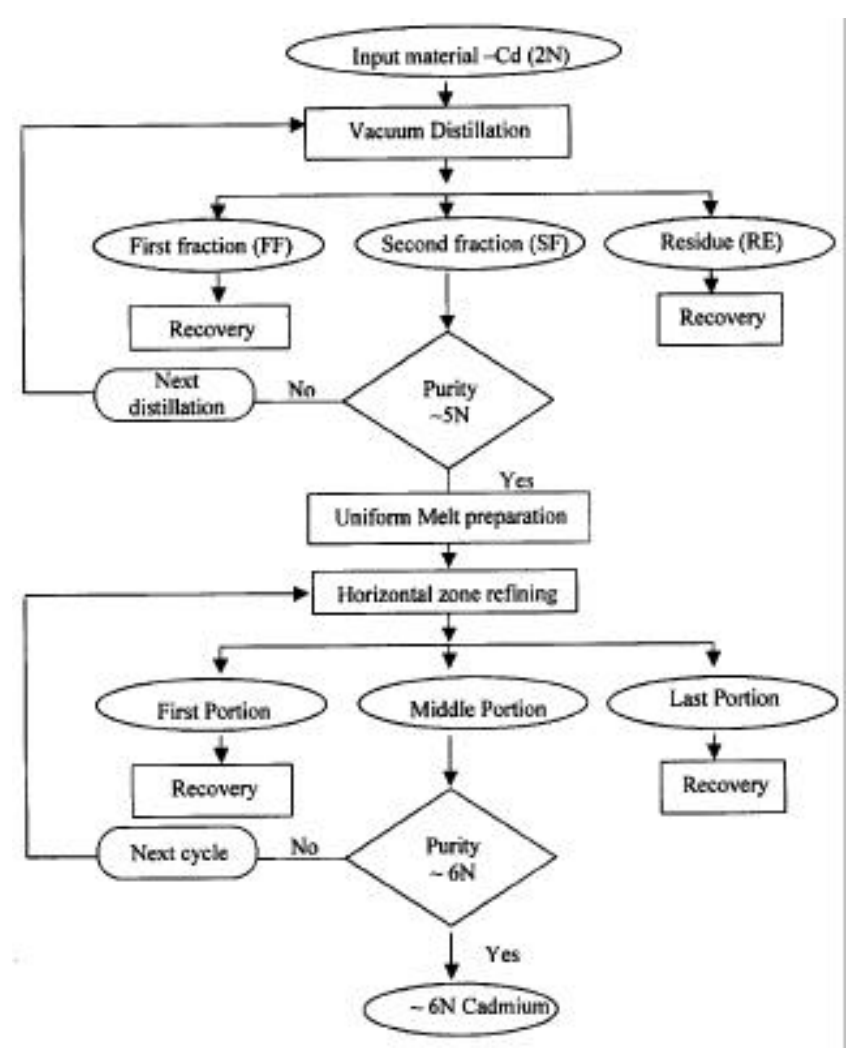

Figure 1. Process flow sheet for cadmium purification. cutter and this middle portion was again uniformly melted to achieve the requisite shape which was used as feed material for the subsequent zone refining cycle. In this manner a total of 4 cycles were completed. Separate and/or cleaned quartz boats of identical sizes were used for each cycle. Tilting angle was used to avoid mass transfer and the hydrogen gas flow was maintained uniformly throughout the experiment. At the end of each cycle, analysis was carried out for the front portion, middle portion and last portion of the ingot which was cut in the ratio of around $1 \cdot 5: 7: 1 \cdot 5$, respectively. While the front and last portions were preserved for recycling, middle portion of the ingot was used for subsequent process of zone refining. After every cycle the front portion, middle portion and last portion samples were analysed to see the impurities content in all the portions. It was normally observed that the content of impurities reduced in the middle portion which reflected in either front or last portion depending on their segregation coefficients in cadmium matrix. In this study the available equipment inductively coupled plasma optical emission spectrometry (ICPOES), was used for the estimation of impurities.

\section{Results and discussion}

The segregation of impurities in each zone pass results in ultimate distribution (UD) after certain number of passes, where no further purification takes place because of the forward flux of the solute on solidification, at a given ingot length $(x)$, is opposed by an equal backward flux due to mixing action in the molten zone. In the present study, among all the trace impurities in cadmium matrix, the segregation coefficient of $\mathrm{Zn}$ (0.4) (Drapala et al 1998), is very near to unity. Keeping $\mathrm{Zn}$ as an extreme case of all the impurities to be removed in cadmium ingot, it is estimated that by rendering 15 passes, the segregation process reaches to UD. This is the basis for planning 15 passes (or 1 cycle) in this experiment. The ICPOES analytical data for the trace impurities in the starting material, i.e. vacuum distilled cadmium metal, and in zone refined

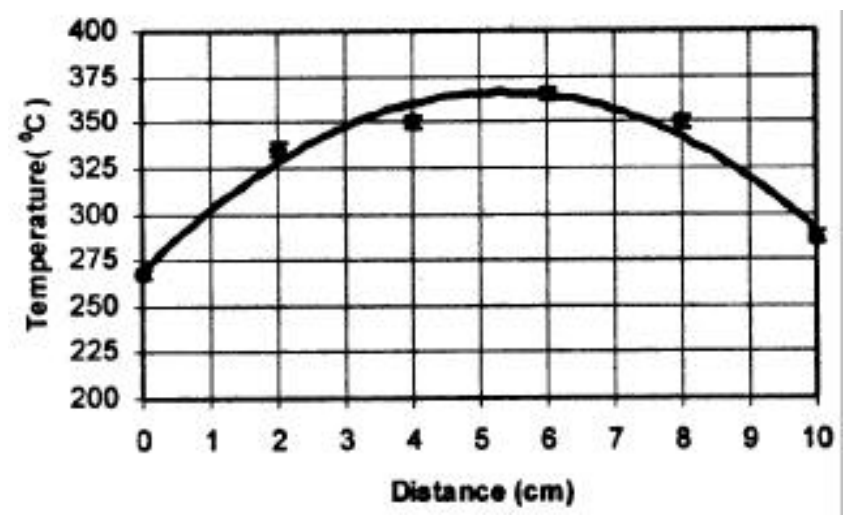

Figure 2. Profiling of zone heater at the operating temperature. 
Table 1. ICPOES analytical data for the trace impurities in cadmium (All values in ppm).

\begin{tabular}{|c|c|c|c|c|c|c|c|c|c|c|}
\hline \multirow[b]{2}{*}{ Sl. no. } & \multirow[b]{2}{*}{ Element } & \multirow{2}{*}{$\begin{array}{l}\text { Starting } \\
\text { material }\end{array}$} & \multicolumn{4}{|c|}{ Middle region after cycle } & \multicolumn{4}{|c|}{ End region after cycle } \\
\hline & & & 1 & 2 & 3 & 4 & 1 & 2 & 3 & 4 \\
\hline 01 & $\mathrm{Ag}$ & $9 \cdot 2$ & $3 \cdot 5$ & $0 \cdot 5$ & $<0 \cdot 1$ & $<0.1$ & 0.76 & 0.65 & $<0.1$ & $<0.1$ \\
\hline 02 & $\mathrm{Al}$ & $<0 \cdot 1$ & $<0.1$ & $<0 \cdot 1$ & $<0 \cdot 1$ & $<0 \cdot 1$ & $<0 \cdot 1$ & $<0 \cdot 1$ & $<0.1$ & $<0.1$ \\
\hline 03 & B & $<0 \cdot 1$ & $<0 \cdot 1$ & $<0 \cdot 1$ & $<0 \cdot 1$ & $<0 \cdot 1$ & $<0 \cdot 1$ & $<0 \cdot 1$ & $<0 \cdot 1$ & $<0 \cdot 1$ \\
\hline 04 & $\mathrm{Bi}$ & $<0 \cdot 1$ & $<0 \cdot 1$ & $<0 \cdot 1$ & $<0 \cdot 1$ & $<0 \cdot 1$ & 0.93 & $0 \cdot 25$ & $<0 \cdot 1$ & $<0 \cdot 1$ \\
\hline 05 & $\mathrm{Cr}$ & $<0 \cdot 1$ & $<0 \cdot 1$ & $<0 \cdot 1$ & $<0 \cdot 1$ & $<0 \cdot 1$ & $0 \cdot 32$ & $<0 \cdot 1$ & $<0 \cdot 1$ & $<0 \cdot 1$ \\
\hline 06 & $\mathrm{Cu}$ & $4 \cdot 5$ & $<0 \cdot 1$ & $<0 \cdot 1$ & $<0 \cdot 1$ & $<0 \cdot 1$ & $65 \cdot 4$ & 31 & $<0 \cdot 1$ & $<0 \cdot 1$ \\
\hline 07 & $\mathrm{Fe}$ & $<0.1$ & $<0.1$ & $<0 \cdot 1$ & $<0.1$ & $<0 \cdot 1$ & $0 \cdot 88$ & $<0.1$ & $<0.1$ & $<0.1$ \\
\hline 08 & $\mathrm{Mg}$ & $1 \cdot 3$ & $<0 \cdot 1$ & $<0 \cdot 1$ & $<0 \cdot 1$ & $<0 \cdot 1$ & $<0 \cdot 1$ & $<0 \cdot 1$ & $<0.1$ & $<0.1$ \\
\hline 09 & $\mathrm{Ni}$ & $5 \cdot 4$ & $<4 \cdot 5$ & $3 \cdot 7$ & $2 \cdot 0$ & $<0 \cdot 1$ & $42 \cdot 5$ & $3 \cdot 61$ & $1 \cdot 02$ & $<0 \cdot 1$ \\
\hline 10 & $\mathrm{~Pb}$ & $14 \cdot 6$ & 13 & 12 & 6 & $<0 \cdot 1$ & 167 & $67 \cdot 3$ & $<0 \cdot 1$ & $<0 \cdot 1$ \\
\hline 11 & $\mathrm{Sb}$ & $<0.1$ & $<0 \cdot 1$ & $<0.1$ & $<0 \cdot 1$ & $<0.1$ & $<1.0$ & $<0 \cdot 1$ & $<0 \cdot 1$ & $<0 \cdot 1$ \\
\hline 12 & $\mathrm{Se}$ & $<0 \cdot 1$ & $<0 \cdot 1$ & $<0 \cdot 1$ & $<0 \cdot 1$ & $<0.1$ & $<0 \cdot 1$ & $<1.0$ & $<0.1$ & $<0.1$ \\
\hline 13 & Sn & 0.2 & $<0 \cdot 1$ & $<0.1$ & $<0 \cdot 1$ & $<0.1$ & $<0.1$ & $<1.0$ & $<0 \cdot 1$ & $<0 \cdot 1$ \\
\hline 14 & $\mathrm{Mn}$ & $<0.1$ & $<0.1$ & $<0.1$ & $<0.1$ & $<0.1$ & $<0.1$ & $<0.1$ & $<0.1$ & $<0.1$ \\
\hline 15 & $\mathrm{Zn}$ & 24.4 & 21 & $12 \cdot 6$ & $2 \cdot 5$ & 0.62 & 230 & 29 & $11 \cdot 3$ & $6 \cdot 42$ \\
\hline
\end{tabular}

material present in the middle and end regions after each successive cycle of zone refining are shown in table 1 .

In our approach, after completing four cycles of zone refining of cadmium (each cycle $=15$ passes) under hydrogen ambient and in a clean room environment of class 10000, the impurities such as $\mathrm{Ag}, \mathrm{Al}, \mathrm{B}, \mathrm{Bi}, \mathrm{Cr}, \mathrm{Cu}, \mathrm{Fe}$, $\mathrm{Mg}, \mathrm{Ni}, \mathrm{Pb}, \mathrm{Sb}, \mathrm{Se}, \mathrm{Sn}, \mathrm{Mn}$ and $\mathrm{Zn}$ were analysed using inductively coupled plasma optical emission spectrometry (ICPOES). The sample preparation for analysis was carried out using sub-boiled acid and nanopure water (18.2 Mohm) by dissolving zone refined cadmium in $1: 1 \mathrm{HNO}_{3}$ in a teflon beaker. The solution thus prepared was fed through peristaltic pump to the plasma of ICPOES through nebulizer using high pure argon gas. Initial content shows the presence of $\mathrm{Ag}(9.2 \mathrm{ppm}, k>2), \mathrm{Cu}(4.5 \mathrm{ppm}, k \ll 1), \quad \mathrm{Mg}$ $(1.3 \mathrm{ppm}, k>1)$, Ni (5.4 ppm, $k \ll 1), \mathrm{Pb}(14.6 \mathrm{ppm}$, $k \ll 1)$, Sn $(0 \cdot 2 \mathrm{ppm}, k<1)$ and Zn $(24.4 \mathrm{ppm}, k=0.4)$. Looking at this scenario, one may conclude that it is easy to remove $\mathrm{Ag}, \mathrm{Cu}, \mathrm{Pb}$ and $\mathrm{Ni}$ but difficult to remove $\mathrm{Mg}$ and $\mathrm{Sn}$. Interestingly the content of $\mathrm{Mg}$ and $\mathrm{Sn}$ in cadmium is almost one order less than $\mathrm{Ag}, \mathrm{Pb}$ and $\mathrm{Ni}$, therefore, they were removed after the first cycle itself. Due to the presence of higher concentration of $\mathrm{Ag}, \mathrm{Pb}$ and $\mathrm{Ni}$ in the starting material, they were removed almost after four cycles. Removal of impurities in a material during zone refining depends on the distribution coefficient of the particular impurity as also the initial impurity content (Feldewerth et al 1994). The impurities, $\mathrm{Ag}$ and $\mathrm{Mg}$, whose distribution coefficient $(K)$ is $>1$, were segregated towards starting position and therefore, the concentration of these impurities, as shown in table 1, is minimum at the end region. It may be noted that removal is always relative and actual value at ppb level depends on the detection limits of the analytical instrument used. $\mathrm{Zn}$ is the relatively most difficult metal to remove in cadmium by zone refining. Hence usually only $\mathrm{Zn}$ content is checked first to see the purity of cadmium. The results show that all the impurities except $\mathrm{Zn}$ have come down below detection limits at the end of 4th cycle. The error percentage (relative standard deviation (RSD)), which is a measure of the variability of data about the mean was calculated using the formula

$$
\mathrm{RSD}=\left[\mathrm{SD} / X^{\mathrm{A}}\right] \times 100,
$$

where, $\mathrm{SD}=$ standard deviation, $X^{\mathrm{A}}=$ average value of measurements. The error percent was calculated for all the values analysed by ICP-OES and was found in the range of 1-2.

\section{Conclusions}

The following conclusions are drawn from this study. At the end of 4th cycle of zone refining, the boron content in cadmium matrix was reduced to $<0.1 \mathrm{ppm}$ using quartz boat while this was $\sim 1 \mathrm{ppm}$ using graphite boat. The stable zones were obtained using quartz boat. On the other hand, it is difficult to maintain stable zones using graphite boat. Zinc impurity in cadmium matrix was reduced from $\sim 24 \mathrm{ppm}$ to $0.6 \mathrm{ppm}$ at the end of four consecutive cycles of zone refining at $3 \mathrm{~mm} / \mathrm{h}$ zone speed and $\sim 65 \mathrm{~mm}$ zone length. The purity of cadmium obtained using this process was $~ 6 \mathrm{~N}(99.9999 \%)$.

\section{Acknowledgement}

The authors are indebted to Dr B K Das, Executive Director, C-MET, for helpful discussion and encouragement.

\section{References}

Bult R P, Bollong A B I and Redden R F 1987 US patent $4,690,725$ 
Capper P and Harris J E 1997 The Bulletin of Selenium-Tellurium 61 Drapala J, Kuchar L and Burkhanov G S 1998 Inorganic Materials 34114

Feldewerth G B, Bollong A B I, Alan B I and Bunnell D C 1994 US patent $5,513,834$

Kovalevsky S V and Shelpakova I R 2000 Chemistry of Sustainable Dev. 885
Kuchar L, Drapala J and Lunacek J 1996 J. Crystal Growth 161 94

Mathur B S and Singh A J 1989 Indian J. Technol. 27218

Munirathnam N R, Prasad D S, Sudheer Ch, Singh A J and Prakash T L 2002 Bull. Mater. Sci. 2579

Zanio K 1978 Semiconductors and semimetals (eds) R K Willardson and A C Beer (New York: Academic Press) 13 